\title{
PROCESSOS IDENTITÁRIOS E A COMUNIDADE QUILOMBOLA LUZIENSE
}

\section{IDENTITY PROCESSES AND THE COMMUNITY QUILOMBOLA LUZIENSE}

\author{
Frank Marcon ${ }^{1}$ \\ Welington Bomfim ${ }^{2}$
}

\section{RESUMO}

Neste artigo, a partir de uma pesquisa etnográfica concluída há seis anos, oriunda de uma demanda para elaboração de um relatório antropológico sobre a Comunidade Quilombola Luziense, analisamos a relação existente entre o tema das identidades e as experiências sociais desta comunidade como construção permanente e contínua de alteridade. Procuramos destacar os processos constitutivos de identificação, percebendo a relação entre memória, solidariedade, "fazer", território e os sensos de coletividade tradicionais. A emergência normativa do direito quilombola, nos últimos anos, materializou um sentimento latente de identificação coletiva advindo de séculos de escravismo e que se reproduziu no longo processo de continuidade de desigualdades não superadas no pós-escravidão. Tais desigualdades nos remetem a necessidade de percebermos as distintas formas de imaginar o trabalho, a liberdade, a propriedade e o território por parte dos "Luzienses", como formas de resistência e demarcadores das diferenças e das identidades que se materializaram no curso dos processos históricos na região Sul de Sergipe, implicados pelas relações de poder advindas do escravismo e do racismo.

Palavras-chave: Quilombos. Processos Identitários. Poder; Luziense. Sergipe.

${ }^{1}$ Doutor em Antropologia, professor na Universidade Federal de Sergipe. Coordenador do Grupo de Estudos Culturais, Identidades e Relações Interétnicas. E-mail: marconfrank@hotmail.com.

${ }^{2}$ Mestre em Antropologia. Doutorando em Sociologia pela Universidade Federal de Sergipe. E-mail: wdobugio@gmail.com 


\begin{abstract}
In this article, from a ethnographic research, completed six years ago, coming from a demand for development of an anthropological report on the Luziense Quilombola Community, we analyze the relationship between the theme of identities and social experiences of this community as permanent and continuous construction of otherness. We seek to highlight the constitutive processes of identification, realizing the relationship between memory, solidarity, "making" territory and traditional collective senses. The normative emergence of quilombola rights in recent years materialized a latent sense of collective identity arising from slavery for centuries and which was reproduced in the long process of continuing inequalities not overcome after the end of slavery. Such inequalities bring us to the necessity of realizing the different ways of imagining work, liberty, property and territory by the Luzienses as forms of resistance and paths of differences and identities that have materialized in the course of historical processes in southern Sergipe, implicated by the power relations resulting from slavery and racism.
\end{abstract}

Keywords: Quilombos. Identity Processes. Power. Luziense. Sergipe. 


\section{Introdução}

No ano de 2008, foi firmado um convênio entre o Incra/SE e a Universidade Federal de Sergipe e iniciamos a elaboração das pesquisas para o Relatório Antropológico da Comunidade Quilombola Luziense ${ }^{3}$, em Santa Luzia do Itanhy, litoral Sul do estado de Sergipe. O relatório foi concluído em dezembro de 2009 e entregue ao órgão nos primeiros meses de 2010. Uma vez entregue, sucederam-se vários procedimentos técnicos e jurídicos que em acordo com o referido decreto apontam para o trâmite da titulação do território, embora a titulação ainda não tenha sido concluída.

Depois de oito anos de iniciado os estudos e depois de seis anos de concluído o Relatório Antropológico, buscamos aqui fazer uma análise retrospectiva sobre a etnografia que realizamos e o fenômeno dos processos identitários (ENNES e MARCON, 2014), amplamente teorizado e discutido nas Ciências Sociais; e as implicações destes sobre a discussão mais geral sobre quilombos no Brasil. Neste sentido, entendemos as identidades como um fenômeno oriundo das relações de poder e dos jogos de posição social, mesmo que não exclusivamente do poder material ou do poder da força física, mas de todas as formas de expressão, também simbólicas de poder, que ao exercerem uma mínima ação expõem uma reação.

No caso que apresentamos, estão imbricados elementos característicos das contradições sociais e econômicas de legitimação da propriedade privada, de exploração da mão de obra servil e da repetição da mentalidade de reprodução das desigualdades por hierarquias sobre a moral e os costumes quando se trata do tema quilombolas. No caso especifico dos quilombolas no município de Santa Luzia do Itanhy há uma coincidência histórica e estrutural comum além de uma afinidade de laços de parentesco, de memória e de território entre os moradores dos povoados do entorno da cidade. Estes se formaram no processo de desestruturação do sistema escravista e servil pós-escravista de propriedade privada e de produção monocultora, pela via da resistência direta à escravidão, por contestação da exploração do trabalho ou como única via de subsistência pela ocupação autônoma, individual e coletiva dos territórios em que passaram a viver.

A seguir, procuramos demonstrar como estes processos de identificação se constituíram acionando elementos de convívio, de memória, de

3 BONFIM, W. MARCON, F. Relatório Antropológico do Território da Comunidade Quilombola Luziense. Aracaju: INCRA/FAPESE, 2009. (Relatório de pesquisa). 
parentesco, de reconhecimento territorial entre si e de diferença cultural, social e econômica com relação aos que não são considerados quilombolas, os considerados distintamente como "outros", ou seja, os grandes e médios proprietários e fazendeiros. Neste sentido a alteridade aparece com mais visibilidade nos momentos de maior tensão, em que esteve e está em jogo a ocupação da terra e o prestígio social, econômico e político dos "outros" na relação com os quilombolas.

\section{Memória e Etnicidade}

A Comunidade Quilombola Luziense está localizada no município de Santa Luzia do Itanhy ${ }^{4}$, que se localiza na região litoral sul-sudeste do estado de Sergipe, distante $86 \mathrm{~km}$ de Aracaju. Localizada à margem direita do rio Piauí, limita-se ao norte com o município de Estância, ao sul com Indiaroba, a sudoeste com Umbaúba, a noroeste com Arauá, a norte-nordeste com Estância e a oeste com Itabaianinha. Os povoados da comunidade quilombola estão localizados em áreas mais próximas aos rios e mangues, sendo que alguns estão em áreas mais baixas, muito próximas à maré, e outros em áreas um pouco mais elevadas do relevo, acerca dos rios. A sede do município está localizada a poucos quilômetros de distância destes povoados.

A produção econômica de Santa Luzia do Itanhy esteve historicamente ligada às culturas de subsistência, principalmente a produção de farinha de mandioca, destinada ao consumo local e ao consumo de outras localidades de Sergipe, da Bahia e de parte de Pernambuco. Paralelo a esta economia estiveram o gado e a cana-de-açúcar. Esta última assumiu um papel importante na vida do município a partir da segunda metade do século XVIII, no chamado renascimento da cultura canavieira no nordeste do Brasil. Daí então a cana-de-açúcar promoveu uma intensa movimentação na economia local. Em meados do século XIX, o município chegou a ter mais de 60 engenhos, onde a mão de obra escrava foi a principal forma de trabalho utilizada, como em quase todo o estado de Sergipe na mesma época (MOTT, 1986). A grande maioria dos trabalhadores dos engenhos foram escravos e em muitos destes

\footnotetext{
${ }^{4}$ Em 12 de julho de 2005, foi emitida pela Fundação Cultural Palmares a Certidão de Auto-Reconhecimento à Comunidade Luziense, aparecendo a nominata dos povoados já mencionadas acima. Em 19 de agosto de 2005, a portaria n. 32, de 12 de agosto de 2005, da Fundação Palmares publicou seu reconhecimento no Diário Oficial da União, na Seção 1, folha 20, o reconhecimento da Comunidade Luziense, com a seguinte redação: [...] Comunidade Luziense, localizada no município de Santa Luzia de Itanhy, pelos povoados Rua da Palha, Pedra Furada, Crasto, Cajazeiras, Taboa, Pedra D'Agua, Bode e Botequim, Estado de Sergipe, Livro 003, Registro n. 261, f. 67.
} 
engenhos se contavam dezenas de homens, mulheres e crianças que trabalham em diferentes tarefas nas fazendas de açúcar.

Alguns destes antigos engenhos se transformaram em usinas durante a virada do século para o XX, mas com a crise da indústria açucareira no nordeste brasileiro e em especial em Sergipe, nos anos sessenta, houve o fechamento destas usinas e um processo de migração bastante complexo e ainda pouco estudado, de trabalhadores e famílias da região, embora muitos tenham permanecido ali, se deslocando para as áreas mais próximas da maré ou se estabelecendo em áreas vizinhas ou ainda dentro das antigas fazendas. Com a decadência do açúcar se intensificou a criação de gado nas fazendas, reconfigurando a economia e a movimentação de riqueza do município entre alguns proprietários. Fora isso, hoje o município de Santa Luzia tem sua economia apoiada na agricultura, principalmente exercida em pequena escala: mandioca, coco e laranja. Sendo a pesca artesanal a principal atividade econômica das localidades ribeirinhas, em que se destacam o aratu, o caranguejo, mexilhões e diversas espécies de peixes.

Toda a área onde hoje estão localizados os povoados de Rua da Palha, Crasto, Cajazeiras e Taboas foram áreas que estiveram próximas das antigas sedes de engenhos e usinas, como: o Engenho São Félix, Castelo, Priapú, São José, Sagüim, Cedro, Priapú, Palha, Pau Ferro, entre outros. Em entrevistas com os moradores mais idosos, dos povoados de Cajazeiras, Crasto e Rua da Palha, se pode evidenciar a relação direta ou indireta de vivências que rememoram histórias de nascimentos e vínculos familiares que indicam as fazendas de engenhos da região ou o trabalho nelas como pontos de referências, bem como também fazem referência ao movimento migratório de outras áreas do estado de Sergipe e da Bahia para esta região por conta das expectativas de trabalho nos engenhos e usinas.

Cabe chamar a atenção para o fato de que os engenhos agregavam famílias de trabalhadores em torno de suas áreas de atuação, tanto para a lida com a limpeza dos terrenos, o plantio, o corte, o carregamento da cana-de-açúcar, mas também para o trabalho de movimentação dos próprios engenhos. Eram moradias temporárias ou permanentes, que contribuíram para dar origem a alguns povoados do município localizados muito próximos das fazendas de engenho. No período da escravidão, eram os escravos que tocavam estes trabalhos que foram gradativamente substituídos pelo estatuto de mão de obra livre.

Percebemos pela tradição oral que há um ponto em comum nas narrativas sobre a ocupação da área onde está localizada a comunidade Luziense. Praticamente todos relacionam seu surgimento ao período de transição do trabalho escravo para o livre na região de Santa Luzia do 
Itanhy. A origem da ocupação do território da comunidade está, repetidas vezes, nos depoimentos dos mais idosos, associada à população afrodescendente e a mão de obra escrava ou livre nas grandes fazendas de engenho da região, como: Antas, São José, Cedro, Palha e, no caso das comunidades em questão, principalmente ligados às fazendas de São Félix, Castelo, Priapú e Sagüim. Todos estes engenhos estiveram em atividade entre as últimas décadas do século XIX e meados do século XX.

Com a decadência da produção de açúcar em meados do século passado, algumas destas fazendas ficaram nas mãos de seus herdeiros ou foram sendo divididas e vendidas para médios e pequenos proprietários. No entanto, boa parte da população que estava ligada ao trabalho com as antigas fazendas continuou estabelecida na região (e hoje faz parte da comunidade), recuando para áreas mais próximas dos rios, da maré e do mangue, em busca de subsistência, ou comprando ou ocupando pequenas áreas dentro das fazendas.

A partir de documentos e depoimentos fomos concentrando as pesquisas em alguns aspectos, pois percebemos como a região de Santa Luzia do Itanhy, repleta de engenhos ou usinas durante um momento significativo de sua história, se tornou um dos lugares agregadores de um tipo social específico de trabalhadores (geralmente afrodescendentes e oriundos de famílias escravizadas) que eram nascidos na região (às vezes nas próprias fazendas de engenho) ou eram migrantes de outras partes do estado, bem como dos estados vizinhos e de trajetórias que também envolviam memórias sobre a escravidão. Pelo que ouvimos dos depoimentos, questionários e em alguns documentos, esta foi uma peculiaridade social caracterizadora da constituição e formação dos povoados que compõe a comunidade.

Outro ponto importante sobre a relação entre a população destas comunidades, o trabalho e o território é que enquanto as sedes das fazendas e as áreas de plantio foram ocupando as áreas secas e mais altas, as áreas de rios e marés eram utilizadas pelos "senhores do açúcar" para o escoamento da produção. Durante o século XIX e XX, tanto o preparo da terra, quanto o plantio, a colheita e o transporte eram realizados pela mão de obra já existente no local (outrora também escrava), mas também por trabalhadores sazonais que às vezes acabavam se estabelecendo no entorno das fazendas ou próximos às marés. As áreas privilegiadas por este tipo de ocupação foram aquelas mais próximas aos rios e mangues por dois motivos: eram áreas menos valorizadas para o plantio, que se localizavam nas franjas das plantações, bem como, eram próximas aos pequenos portos de escoamento, com algum pedaço de terra no qual se podia manter uma roça doméstica e as práticas de pesca e catado. Nestes locais, 
principalmente, surgiam aglomerados de trabalhadores das fazendas de engenho, com suas casas de taipa ou palha localizadas dentro do que era considerada propriedade do engenho, assim como, alguns destes trabalhadores conseguiam, ainda, comprar ou ocupar pequenas áreas por ali localizadas, pouco valorizadas para o plantio, por serem alagadiças e irregulares, estando muito próximas as marés e rios.

A atividade econômica ou o trabalho exercido nos territórios da Comunidade Luziense também se tornaram agregadores de sentimento coletivo compartilhado sobre a geografia local como lugar de identidade. Segundo os depoimentos que colhemos entre alguns moradores, por mais que a palavra "quilombo" fosse estranha a alguns como sentido, os sentimentos de solidariedade coletiva já existiam na Comunidade Luziense desde os tempos imemoriais da sua formação intrincada com os tempos da escravidão. Na Luziense, o sentido de comunidade passa por um idioma de solidariedade esboçado pelos sentidos dados a convivência coletiva por parte dos seus moradores, que aponta para a memória da escravidão e pela exploração do trabalho por parte do sistema produtivo das fazendas.

Halbwachs (2004, p. 159) refletindo sobre a relação entre a memória social e os lugares diz que há tantas maneiras de representar o espaço quantos sejam os grupos que nele habitam e, neste caso, os moradores da Luziense instauraram uma percepção social comum, em que a memória sobre o lugar e os entendimentos sobre distribuição da ocupação e dos usos do território são compartilhados, assim como as regras de sociabilidade são evidenciadas pela cumplicidade das relações afetivas entre eles. As reproduções das lógicas de convívio são tradicionalmente reiteradas internamente em oposição às lógicas exteriores à comunidade que são as lógicas de expropriação do trabalho e o modelo de vida social extremamente oposto entre a história dos senhores ou fazendeiros e suas famílias versus a deles, a dos moradores dos povoados, trabalhadores ou seus descendentes.

Os povoados do Bode, Cajazeiras, Crasto, Pedra D'Agua, Pedra Furada, Rua da Palha e Taboas formaram-se a partir de um mesmo contexto histórico de trabalho nos engenhos e ocupam a mesma região topográfica, realizando as mesmas atividades de lazer, de trabalho e de subsistência e mantêm relações tradicionais de afinidade e parentesco comuns, como aprofundaremos adiante. Tais moradores da Comunidade Luziense são muito enfáticos nas referências de alteridade com relação a "outros" atores sociais da região, como os fazendeiros e moradores de outras localidades. Não bastasse tal caracterização empírica, os quilombolas da Luziense também se definem pela consciência de comunidade, baseada no argumento de que detém uma origem comum e uma vida social e moral comum. 
Neste sentido, gostaríamos de chamar a atenção para dois pontos que relacionam nossas observações empíricas aos conceitos de identidade e de etnicidade e o que viemos chamando de processos identitários (ENNES, MARCON, 2014). Recuperando Max Weber (2004), entendemos que os "grupos étnicos" são grupos sociais que alimentam uma crença subjetiva em uma comunidade de origem fundada nas semelhanças de aparência externa, dos costumes ou nas lembranças da colonização ou da migração, de modo que esta crença se torna importante para a propagação da comunalização, às vezes pouco importando se a comunidade de sangue existe de fato. Isto quer dizer que a crença subjetiva na origem comum é uma construção social, um processo de longo curso, em que as posições de identidade vão se movendo e moldando no decorrer das relações e influenciadas pelas estruturas. Não é o isolamento que cria a consciência étnica, mas a comunicação, a interação social entre os sujeitos e que faz emergir os sentidos de diferença quando se estabelecem os jogos de posição social e hierarquia. Para entendermos este processo é necessário levarmos em consideração

a) os atores sociais de algum modo articulados a grupos, b) os motivos de disputas de pertencimento ou não a tais grupos, c) os elementos morais e normativos que regulam o meio pelos quais estes atores entram em interação pelo que disputam e d) os contextos históricos e sociais nos quais são produzidos e, ao mesmo, contribuem para sua produção (ENNES, MARCON, 2014, p. 277).

Neste sentido, os quilombolas enquanto categoria social são grupos de identidade étnica que abrigam a crença subjetiva numa procedência comum, que se afirma por meio de seus agentes, que reivindicam o reconhecimento enquanto comunidade e a titulação de suas terras enquanto direito, que refletem o efeito do aparato regulador e normativo recente e das lutas dos movimentos sociais negros e que emerge da denúncia de um contexto histórico e social extremamente polarizado pelas diferenças sociais econômicas que se reproduzem há séculos, marcadas por hierarquias de classe e pelo racismo. A formação da Comunidade Quilombola Luzieneses está ligada à história da escravidão e à ideia de afrodescendência e se fundamenta no argumento da tradição e da semelhança de costumes e principalmente na relação de oposição entre "eles", os proprietários e fazendeiros, e o "nós" descendentes de escravos, trabalhadores e moradores dos povoados. A conduta diária da vida, a relação de oposição social e a homogeneidade das condições e das práticas comunitárias cotidianas constituem os elementos ativos no fortalecimento dos seus sentimentos de identificação coletiva, em que a ideia de comunidade aparece muitas vezes amparada. 
Para Fredrik Barth (1998) não existe o grupo como essência primordial, mas a formas de autoatribuição que são consignadas as categorias étnicas que reforçam as noções sobre origens comuns. Entendermos a etnicidade a partir de Weber e Barth é percebermos como se manifesta o repertório de referências caracterizadoras do "nós" versus os "outros" e considerarmos que tal atribuição pode ser conflituosa ou negociada na inter-relação dentro/fora, o que confere o entendimento de dinâmica interacional à definição das identidades étnicas. Tais reflexões nos ajudam a pensar as comunidades quilombolas como comunidades de solidariedade assentadas no argumento de "origem comum", com base na memória de suas próprias experiências e nos sentidos dados por eles as contradições que emergem daí. De algum modo, a etnicidade serve como categoria para observarmos como as comunidades de solidariedade, assentadas no argumento de origem comum e compartilhada, se definem a partir de significantes de diferença que estabelecem as fronteiras entre nós/eles e passam a situar seu surgimento em algum tempo mítico.

\section{Ocupação do território}

Um dos elementos mais significativos que emergiram de nossas pesquisas junto aos moradores dos povoados de Bode, Cajazeiras, Crasto, Pedra D’Agua, Pedra Furada, Rua da Palha e Taboa fora a construção dos sentidos com relação à identificação quilombola e sobre a definição da delimitação do que seria o território da comunidade. Destes pontos destacamos duas questões: primeiro, que um senso de comunidade esteve aí presente desde há muito tempo em toda a região, marcada pelos significantes da memória sobre a escravidão e sobre o trabalho, sobre as relações de parentesco, sobre a economia, sobre a geografia e sobre a política local, muito antes de o processo ser aberto, reivindicando a titulação. Segundo, que as características da ocupação fundiária na região remetem, de um lado, a tradição da grande propriedade adquirida por compra e venda ou por herança dedicada às economias extensivas, advindas das lógicas escravocratas de ocupação do solo, de relações de trabalho e de produção econômica, e de outro lado, a da ocupação de pequenas áreas de solo para subsistência por parte dos trabalhadores e de seus familiares.

No Sul de Sergipe, esta ocupação ocorreu dentro das grandes propriedades (em área definida pelos grandes proprietários) ou fora delas, em terrenos acidentados e consideradas não produtivos em termos extensivos (pela proximidade com os mangues, por exemplo). Os dois fatores são importantes porque irão atuar como constituidores do sentido coletivo de comunidade e sobre o sentido de identificação com o 
território Luziense que se firmará entre aqueles que viveram e vivem na região há muitas décadas. São familiares e descendentes de escravos e de trabalhadores que formaram núcleos familiares que foram se convertendo em povoados às margens das médias e grandes propriedades. Estas, por sua vez, foram se reconfigurando, do ponto de vista fundiário, a partir da decadência dos sucessivos ciclos econômicos da região. Ou seja, aí a questão fundiária é extremamente desigual e reprodutora das contradições dos tempos do escravismo. Este é um elemento-chave para compreendermos a questão quilombola em Santa Luzia do Itanhy e região. Uma área de grandes fazendas no entorno da cidade, em que a terra é sinônima de prestígio econômico, social e político, pulverizada por povoados e ocupações isoladas e formadas por descendentes de escravos, trabalhadores sazonais e pequenos proprietários.

As localidades de Rua da Palha e Crasto se formaram em períodos próximos. Essa ocupação tem relação direta com a Usina Castelo, uma das maiores da região. A cana-de-açúcar foi o fator inicial de formação das comunidades. No entanto, após a "decadência" da cana-de-açúcar a propriedade passou por uma fragmentação. Partes das terras foram negociadas, o que se estendeu desde o início do século XX. Os novos proprietários não seguiram as mesmas formas de uso das propriedades. Alguns investiram na extração da madeira do mangue e na plantação de coco, ao passo que outros investiram em gado e agricultura.

A produção açucareira na região é presente desde o século XVII, mas é a partir de século XIX que sua produção ganha grandes escalas (NUNES, 1996). Talvez os sinais físicos mais significativos daqueles tempos remotos, sejam a arquitetura das sedes das atuais fazendas Castelo e São Félix, bem como as ruínas dos antigos trapiches por onde se escoava a produção açucareira. Por exemplo, o antigo trapiche da localidade de Priapú da Feira, ainda é utilizado como porto pelos moradores, apesar das restrições de uso pelo atual proprietário das terras onde o mesmo está localizado. Segundo os moradores dos povoados mencionados, o trapiche Priapú da Feira serviu, principalmente, para o escoamento da produção do Engenho, depois Usina do Priapú, vizinha da região ocupada hoje pelos moradores da comunidade.

Após a abolição da escravatura, para manter a continuidade da produção, fora necessária uma quantidade expressiva de trabalhadores. Muitos ex-escravos possivelmente continuaram prestando serviço nas propriedades e assim foram se mantendo na região. Cabe salientar que o mesmo deve ter acontecido com outros engenhos, já que nas primeiras décadas do século XX, esta ainda era uma atividade econômica importante para o município. A importância dos engenhos, da vida social em torno deles e da relação dos trabalhadores e suas famílias com 
os mesmos são revelados pelos registros de casamentos e nascimentos do final do século XIX e início do século XX. Alguns exemplos, como as referências de moradia, indicando a Fazenda Castelo ou a Usina do Priapú são significativos para se entender as referências de reconhecimento público a tais espaços sociais daquele período.

Hoje, alguns moradores das comunidades são proprietários legais de seus lotes, alguns possuem registro de posse, outros de compra e escritura, alguns têm apenas recibos de compra e venda e outros não têm documento algum de seus lotes. Alguns alegam pagar os impostos devidos (às vezes cadastrados no próprio INCRA). Porém, a maioria inclui-se na categoria de "posseiros" e as posses são reconhecidas entre eles. As ocupações dos terrenos deram-se no transcorrer dos tempos, resultado de relações dos trabalhadores com os proprietários das fazendas. Algumas vezes como forma de pagamento, outras na modalidade de parcerias, outras pela compra e ainda outras pela ocupação. As concessões de moradia e produção foram uma prática remota de meados do século XX, que alguns dos entrevistados narraram em conversas informais.

Na sua maior parte, as terras do antigo Engenho ou Fazenda Sagüim e da Usina do Priapú avançavam por sobre boa parte do que são os povoados Cajazeiras e Taboas. As terras de tais fazendas foram sendo repartidas por heranças e por vendas, o que aproximou as cercas dos novos proprietários de fazendas de coco e gado das famílias da comunidade. Tal processo foi acelerado depois da metade do século XX, quando a produção do açúcar entrou em franca decadência. Por outro lado, a região mais próxima ao mangue, parte da Cajazeiras, Bode e Pedra D'Agua, já era ocupada por posseiros e pequenos proprietários de sítios, muitos deles descendentes de africanos nascidos na região, outros vindos da Bahia, de Alagoas ou do interior do estado de Sergipe, como foi recorrente ouvirmos nos depoimentos.

\section{Trabalho e Economia}

O trabalho com a cana-de-açúcar não é e não foi unanimidade entre os moradores da comunidade. Desde meados do século XIX, a mandioca e o coqueiro aparecem como produção econômica na região. Pesquisas que realizamos sobre os inventários, no Cartório de Estância, demonstram que as propriedades de terras e suas produções estavam associadas a tais culturas agrícolas e remontam muitas décadas atrás. Outro trabalho comum é a atividade pesqueira e de catado de crustáceos, que aparece como informação nos depoimentos orais e na nossa observação direta e remontam a própria ocupação humana às 
proximidades dos mangues. É interessante salientar que, para a comunidade, a pesca é uma atividade econômica às vezes principal, às vezes complementar, às vezes de subsistência, assim como a mandioca e o extrativismo de frutas. Já o coco, a cana-de-açúcar, o gado e a extração de madeira geralmente são atividades associadas aos fazendeiros, para quem alguns dos membros da comunidade prestam ou prestavam serviços sazonais.

Outra atividade dos moradores da comunidade são as chamadas "roças de meia". Nesta forma de relação produtiva, o proprietário cede um pedaço de terra para uma pessoa ou família dos quilombolas que vão "limpar" e depois preparar a terras para o plantio. Eles cuidam da roça e na colheita uma meia parte é destinada ao dono da terra. O dono da terra recebe a terra de volta, agora limpa (sem mata) e em alguns casos já com o capim plantado para o gado. A família que realizou o plantio e ficou com "uma meia", leva agora a mandioca para a casa de farinha. Cabe destacar que a mandioca ainda é uma das principais fontes de renda e alimento dessa população. Pelo menos daquelas populações que contam com algum espaço de plantio, seja em negociação com proprietários, seja por liberação total da terra para o uso, o que não ocorre com frequência pela animosidade das relações. Por exemplo, por falta de acesso à terra cultivável, o povoado do Crasto $^{5}$, em 2009, já vivia exclusivamente dependente da pesca ou do catado de crustáceos e mariscos, dos pequenos comércios locais e de alguns cargos públicos na prefeitura municipal.

Nos demais povoados, a produção farinha há muito tempo é destinada ao consumo e uma parte é vendida nas feiras da região. A produção de farinha nunca deixou de existir na Luziense. Só em Cajazeiras, Pedra D'Agua e Taboas encontramos oito casas de farinha em atividade, comunitárias ou familiares, sendo esta uma importante atividade tradicional, tanto no que diz respeito à subsistência, quanto no sentido da coesão social promovida pela relação entre as etapas de produção e as relações de trabalho familiar e comunitário. O preparo da terra, o plantio, a colheita, a produção da farinha, bem como as atividades pesqueiras, são todas atividades coletivas de suma importância para os quilombolas, pois envolvem os diferentes membros dos núcleos familiares, sejam homens ou mulheres, adultos ou crianças.

\footnotetext{
${ }^{5}$ No Crasto, a produção de farinha era inexistente quando realizamos a pesquisa, ao passo que até meados dos anos 60, ainda existiam casas de farinha na localidade. $O$ problema foi a proibição de cultivo da mandioca nas únicas terras disponíveis para plantação, localizadas na Fazenda Caísa. Segundo os moradores, quando o proprietário proibiu esse uso das terras, a produção de farinha sofreu queda significativa e aos poucos as casas de farinha foram fechando, e algumas delas virando residências.
} 
Nos últimos anos, alguns proprietários de terras (que não são considerados membros da comunidade) reforçaram as barreiras físicas para o acesso dos moradores dos povoados às suas terras, mesmo nos pontos que antes eram considerados de travessia até o mangue ou o rio e que cruzam por tais propriedades. Estes proprietários passaram a construir cercas, dificultar e guarnecer as passagens. A lavoura, a pesca e o extrativismo são atividades que em virtude do aumento demográfico, mas também das proibições dos fazendeiros, tem se tornado cada vez mais restritas e insuficientes para o bem estar coletivo e a manutenção das redes de relação social e dos costumes em um território que é tradicionalmente ocupado pela Comunidade Quilombola Luziense.

\section{Sensos de Comunidade, de Pertencimento e de Convívio}

Na comunidade Luziense, as relações de parentesco perpassam distintas formas de convívio. De maneira geral, o parentesco é uma referência de legitimidade de pertencimento à comunidade. No entanto, a consanguinidade não é a forma exclusiva de definição deste pertencimento. As uniões conjugais são estabelecidas através da absorção corrente de novos membros, sem que existam regras ou normas reguladas de endogamia ou exogamia na comunidade. Entre os povoados mencionados, evidenciamos empiricamente relações de parentesco efetivadas pela circulação das pessoas e pela convivência em situações de trabalho e lazer. São composições familiares distintas, diversificadas e numerosas, sendo impossível estabelecer uma genealogia única para a comunidade, embora as famílias estejam sempre se conectando e constituindo alianças em ou outro momento. De certa forma, o que identificamos como recorrentes foram sentidos de parentescos mais imaginários do que consanguíneos. Um sentido de comunidade que se revela na ideia de família extensa. Este parentesco está mais relacionado às alianças e as redes de afeto e de solidariedade.

A "crença" numa origem social comum, como a que apontamos acima, é o que potencializa e substancializa também a ideia de sentimento comum de familiaridade na comunidade. As pessoas mais idosas são respeitadas por todos e muitos são tratados como padrinhos e madrinhas pelos demais, como detentores dos saberes tradicionais da comunidade. Sempre que visitávamos os povoados e pedíamos por informações sobre o território, os costumes e a história da comunidade, as pessoas nos indicavam os mais idosos, nos levavam até eles e faziam algum sinal de respeito para com eles, chamando-os de madrinha, padrinho, avô ou avó. Em vários momentos, durante conversas informais e entrevistas, ouvimos várias afirmações do tipo "aqui todo mundo é parente", fazendo referências a avós, pais, tios, irmãos, primos, sogros e 
cunhados, de maneira generalizada e em sentido de acolhimento. Alguns lotes e residências comportam casas ou aglomerados de casas de grupos de familiares onde as atividades domésticas e produtivas são divididas entre homens e mulheres e entre as diferentes gerações. Mesmo assim, algumas pessoas se deslocam do núcleo familiar migrando para outras terras dentro do povoado ou da comunidade por diferentes motivos, entre eles, por situações de oportunidade de trabalho, de proximidades da escola ou dos postos de saúde e, entre outros, por uniões conjugais, dando a sensação de que as redes familiares estão todas conectadas.

Quando coletamos as genealogias percebemos o quanto estas conexões entre as famílias são uma característica local, mas também percebemos como a comunidade Luziense foi se constituindo a partir de diferentes troncos familiares. A maior parte está estabelecida na região há mais de um século. Em vários momentos da história da comunidade, familiares dos povoados do Bode, Crasto, Cajazeiras, Pedra D'Agua, Pedra Furada, Taboas e Rua da Palha acabaram efetivando relações conjugais entre eles. Talvez por isto a afirmação de que "todos são parentes" seja uma constatação coletiva na Luziense, mesmo que estejamos diante de uma realidade de mais de 800 famílias. Alguns dos troncos familiares mais lembrados na comunidade são: Caetano, Conceição, Costa, Gama, Muniz, Nascimento, Oliveira, Pereira, Pirangi, Reis, Serafim, Timótio e Santos. Não foi possível apontarmos com precisão as datas de chegada de muitas destas famílias, pela falta de documentação de registro civil dos antepassados, mas ouvimos dos depoimentos de representantes destas famílias que eles estão na localidade há mais de cem anos, como afirma o senhor Costa (com 83 anos à época), que seu pai, Jerônimo Costa dos Santos, e seu avô, Marcos Costa, nasceram na comunidade e que as terras onde vive a família foram herdadas de Zé da Costa, pai de Marcos da Costa, ou seja, seu Costa recupera uma memória de mais de um século e algumas décadas de presença da família no lugar.

Na Comunidade Luziense, a relação da família com a terra e seus modos de trabalho representa um elemento fundamental para compreendermos algumas regularidades sociais, associando algumas continuidades entre o presente e o passado. $O$ fim da escravidão, o fim da produção de açúcar em larga escala na região, o fenômeno de migração do interior para o litoral no Nordeste brasileiro caracterizaram um momento peculiar do contexto de fixação das famílias citadas na área em questão. Os motivos são a descendência direta dos escravos que se encontravam nos engenhos da região no final do século XIX; a descendência de exescravos que, ainda no século XIX ou já no XX, vieram trabalhar na região oriundos de outras zonas açucareiras; e a origem das famílias que migraram para a região em busca de trabalho, vindas principalmente do sertão do Nordeste, especialmente de Sergipe, Bahia e Alagoas. As alianças que se formaram entre as pessoas que chegavam de outras 
regiões e as pessoas nascidas no local foram se consolidando pelas formas de uso coletivo do solo, do trabalho, da subsistência no mangue e da vida cotidiana, religiosa, festiva e moral, marcando as transformações no quadro demográfico da comunidade.

Quando falamos em pertencer a uma família ou em morar na localidade - do ponto de vista da comunidade Luziense - não se trata apenas de habitar, mas sim de participar das atividades sociais na localidade (laborais, religiosas, lúdicas). Esse critério de pertencimento perpassa pela relação de solidariedades mútuas que as famílias construíram e estabeleceram entre si. Para além do casamento, um elemento fundamental da aliança social é também o apadrinhamento entre vizinhos da comunidade. Este mecanismo estabelece ou reforça laços de aliança entre indivíduos e grupos. Ser padrinho ou afilhado representa o estreitamento recíproco da familiaridade entre as pessoas. O que faz da consideração e do respeito mútuo um vínculo moral, no qual a consanguinidade e mesmo o casamento não são os únicos critérios.

Dessa forma, as relações de parentesco, que certamente foram formadas no entorno de diferentes contextos históricos na região, indicam redes de reciprocidade que acabaram ligando as famílias que moram nas diferentes localidades da Comunidade. Nos dias de hoje, podemos acrescentar que outros espaços de sociabilidade potencializam o surgimento de novos namoros e alianças. Espaços sociais como os das escolas, das igrejas e das praças tornaram-se oportunos para construção de novos laços familiares na comunidade. Se em certos momentos as pessoas se aproximavam das outras por meio de suas atividades laborais (serviços nas grandes propriedades, venda e compra nas feiras de excedentes de produção familiar, trabalhos nas lavouras e no mangue) e das festas tradicionais, hoje, as salas de aulas, o pátio da escola, o transporte escolar, os espaços públicos de reuniões festivas e religiosas representam importantes formas de ligação entre as pessoas, famílias e povoados.

O critério de nascer e de morar na comunidade é o mais recorrente quando eles definem quem faz parte desta coletividade, mas é interessante ressaltar que não é exclusivamente o morar na localidade. Existem razões ponderáveis entre morar e ser aceito como membro da comunidade que passam por outros critérios como as alianças e o parentesco, bem como o convívio e a empatia coletiva. Quando os moradores se casam com pessoas de outros lugares, essas passam a fazer parte da comunidade desde que vivam na comunidade. Com o convívio, a aceitação vai se constituindo em torno das relações que se estabelecem com outros membros. 
Desta maneira, existem algumas atitudes esperadas, que confirmarão a inserção das pessoas no grupo. Novos membros foram e são incluídos e aceitos pelo casamento, por herança e vez por outra pela compra de uma pequena propriedade, ou ainda pelo retorno de uma experiência migratória, desde que demonstrem compartilhar das experiências sociais estabelecidas na comunidade, bem como estabeleçam vínculos afetivos com os membros tradicionalmente estabelecidos. Participar das atividades laborais e festivas é um dos critérios de confirmação desse pertencimento, assim como vivenciar as experiências de solidariedades sobre o uso do território, que implica no respeito aos usos coletivos costumeiros do solo, da mata, dos mangues e dos rios (e as atividades de roça, extrativismo, catado e pesca).

O critério da moradia está diretamente ligado ao critério de legitimidade pelo parentesco. Em alguns casos isolados, há pessoas que moram na comunidade, mas não mantém relações de parentesco com nenhuma das famílias locais mais tradicionais da comunidade. Algumas dessas pessoas são pescadores que vieram de outras localidades do mesmo município, ou de outros, são funcionários das escolas ou postos de saúde ou, ainda pequenos agricultores. Neste caso, o convívio com a pesca, com o catado, com a roça ou outras atividades comuns na localidade, mais o convívio social podem torná-las, depois de certo tempo habitando o espaço, reconhecidas como pertencentes à comunidade ${ }^{6}$.

Por outro lado, os grandes fazendeiros do entorno dos povoados; aqueles que têm casas de veraneio dispersas pelo território; os proprietários de sítios que não consideram a "casa" na comunidade como a sua casa de moradia e o seu lugar de pertencimento; todos estes são pessoas e famílias que podem não ser reconhecidas como fazendo parte da comunidade. Mesmo que eles permaneçam ativamente na localidade, frequentando suas propriedades, mantendo-as cercadas, não criaram vínculos com as práticas afetivas, laborais, simbólicas da comunidade e, muitas vezes, demarcaram alguma distinção também econômica, principalmente no que diz respeito ao critério produtivo local, ou desenvolvem atividades que excluem completamente os membros da comunidade, ou desenvolvem algum tipo de exploração de sua mão de obra e do território considerado comum. Tais pessoas são consideradas como não pertencentes à Comunidade Quilombola Luizense, como "o

\footnotetext{
${ }^{6}$ Quanto aos casos de moradores que migraram para outros locais (como o Sudeste do País, para onde se aventuram muitos moradores da região em busca de trabalho) e voltaram, segundo Dona Conceição: “.... se eles tem família aqui, então a gente aceita... é como se eles tivessem voltando pra casa né?..." (Depoimento cedido em maio de 2009). É claro que em todos os casos existiram e existem variáveis que são da própria dinâmica das relações sociais e dos costumes, legitimadas pela empatia e pelo convívio diário.
} 
outro" ou como "de fora", e pouco aparecem para conversar abaixo da sombra das árvores, nos pontos de encontro e de sociabilidades diários, nas reuniões comunitárias, nas atividades produtivas coletivas e não compartilham das memórias, dos costumes, das angústias e das alegrias cotidianas da comunidade.

\section{Sociabilidades e Solidariedades}

Durante a etnografia nos deparamos com muitas atividades de fazer coletivo. Entre elas, atividades de trabalho e de lazer. Sobre o lazer, muitas atividades são realizadas à margem dos rios ou da maré, mas também nos campos de futebol da comunidade, nas sedes de associações e nas praças, becos ou ruas. Algumas realizadas geralmente nos finais de semana, como as reuniões lúdicas dos acampamentos na maré, os jogos de futebol e as festas nas associações. Outras, costumeiramente realizadas há muito tempo na comunidade, não dependem do dia da semana, mas estão relacionadas com as atividades produtivas. Exemplo da plantação de mandioca, quando se formavam grupos chamados de "batalhões", para limpar e preparar um determinado espaço para o plantio. Os homens pegam na enxada e as mulheres preparam a comida do almoço. Enquanto isso, as crianças se divertem nas matas com a coleta de frutas e a captura de crustáceos.

Em outros tempos, esta forma de trabalho/entretenimento colaborativo era corriqueira. Terminada a limpeza, estando na hora de servir o almoço, os ânimos são revigorados com algumas doses de aguardente e um prato de moquecas, cozidos ou feijoada. Quando alguém anima ou animava a festa, como os cantadores de samba de coco, esses mutirões se estendiam pela noite adentro. A dança e a música passavam a ditar o ritmo dos encontros. De qualquer modo, vale ressaltar que nos dias de hoje permanece a atividade de caráter coletivo na pesca e na agricultura, terminando ou não em entretenimento, o que caracteriza a sociabilidade na comunidade, tanto entre as atividades festivas como entre as atividades de trabalho.

$\mathrm{Na}$ atualidade, a relação do trabalho com os sentimentos de identidade está, principalmente, ligada às práticas da pesca, do catado e do roçado, bem como em tudo que estas atividades envolvem, por exemplo, no caso da roça de mandioca, desde o preparo da terra ao feitio da farinha, e no caso do catado, desde a ida ao mangue até quebrada ou limpeza dos crustáceos. Como já destacamos, tais atividades são a força na sobrevivência dos moradores, deixando de serem complementos para se constituírem na principal fonte de alimento, de renda familiar e de coesão social da comunidade. 
Os povoados que formam o Quilombo Luziense estão distribuídos em uma região com forte presença de feiras livres. A antiga feira do Priapú, a feira de Santa Luzia do Itanhy e o porto do Crasto são locais onde se criaram e se mantinham e mantém relações de comércio e reciprocidade que conectam os povoados entre si. Além de compra e venda de objetos e produtos, esses locais são lugares de sociabilidades e encontro entre os moradores dos povoados e da região. A dinâmica nas feiras livres é muito parecida nos diferentes lugares em que são realizadas. Boa parte das pessoas que as frequentam também realizam uma espécie de circuito nos dias e pelas localidades onde as feiras ocorrem. As saídas para ir à feira são momentos que oportunizam as pessoas estabelecerem contatos e encontros com pessoas da comunidade e com outros de fora dela.

Algumas sociabilidades podem estar relacionadas às atividades religiosas. Muitos se reúnem em tordo das capelas e igrejas em horários periódicos de reza, outros se reúnem nas casas convertidas em templos religiosos evangélicos e outros em torno dos cultos afro religiosos, sendo que em muitos casos estas fronteiras de religiosidade formal não estão bem definidas. A presença institucional mais visível e tradicional é a da Igreja Católica, com os prédios de igrejas e capelas.

No período de grande produção de açúcar na região, no final do século XIX e do início até meados do século XX, já ocorriam algumas festas promovidas pela Igreja. A relação dessa produção econômica com a religião é demonstrada por alguns documentos que encontramos nos arquivos. A manutenção das festas religiosas locais é uma perpetuação das tradições, que agregou a elas valores simbólicos. A festa tem uma importância fundamental no estabelecimento de redes de reciprocidade e sociabilidade, envolvendo muitas famílias na sua preparação e mais gente ainda nos festejos. A Festa do Pescador no Crasto e a Festa do Senhor do Bonfim, em Cajazeiras, estão entre as mais reconhecidas e fortes. Outros festejos como os de São João, as comemorações pelo nascimento, pelo casamento e dedicadas aos santos padroeiros de pessoas e famílias também foram e são recorrentes.

Desta forma, os momentos de entretenimento, as atividades sociais de trabalho e as expressões religiosas estão caracterizadas pela correlação e continuidade entre elas, articuladas as memórias das pessoas sobre a presença da comunidade no território, demonstrando seus vínculos com a mata, os rios, os mangues e a arquitetura profana e religiosa. Ou seja, a comunidade vivencia e reconhece uma perspectiva utilitária, sensível e simbólica da geografia do território tradicionalmente ocupado por eles. Um vínculo com um passado de origem que remete aos tempos da escravidão e as experiências alternativas de construção de um espaço comunitário e coletivo de liberdade. 


\section{Considerações Finais}

Em março de 2016, visitamos novamente a comunidade e alguns de nossos interlocutores afirmaram que nada mudou com relação às terras depois de finalizado o Relatório Técnico de Identificação e Delimitação, pois o processo ainda se encontra em fase de tramitação judicial. Algumas contestações jurídicas ocorreram e o caso foi para Brasília, não tendo perspectiva de prazo para o seu prosseguimento. $O$ fato é que algumas pessoas da comunidade que prestavam serviços sazonais para os grandes proprietários das terras agora contestadas como quilombolas e outros que tinham autorização para circular ou para plantar roça nestas terras foram impedidos de entrar nas propriedades, isso, possivelmente, como forma de represália contra a reivindicação movida pela comunidade.

A demanda quilombola mudou a vida das pessoas. Porém, boa parte delas desconfia que o território seja titulado em nome da comunidade por desacreditar que se pode romper com velhos ciclos de poder estabelecidos. Aparentemente, a ideia de "ser quilombola" gera controvérsias por conta de sua eficácia, mesmo entre os outrora mais entusiasmados, aqueles que acompanhavam o processo na esperança de ter uma condição melhor de vida, com direito a terra e seu território delimitado e titulado. A judicialização dos processos de titulação e o longo período de espera deixam os quilombolas desiludidos com o futuro da demarcação territorial, além de piorar as relações com alguns dos fazendeiros das terras contestadas. Isto não significa que se tenham desconstruído os sentidos de solidariedade comum entre os moradores dos povoados aí implicados, muito pelo contrário, com a abertura do processo se fortaleceram os laços pelo reconhecimento de sua existência e de sua cultura por parte das esferas públicas do Estado e foram abertas possibilidades reais e de luta por autonomia econômica e política, geradas com a expectativa de titulação do território.

O processo de identificação entre os "luzienses" vem se constituindo há décadas, através das formas de compartilhar o solo e a produção, das relações de afinidade e afeto, dos significados simbólicos do território, das memórias e das experiências sociais compartilhadas entre eles e contrastadas em oposição nas relações cotidianas com outros agentes de memória e poder. Outro ponto fundamental do processo de identificação são as motivações pelas disputas de pertencimento ou não, que neste caso tem relação com a reivindicação simbólica do reconhecimento e material do território em que se vive. $\mathrm{O}$ aparato legal da Constituição de 1988 e o Decreto 4887/03 legitimaram a via legal pelas demandas pelas quais os quilombolas passaram a reivindicar formalmente seu senso coletivo de comunidade e os direitos dele advindos. O contexto histórico

e social em que esse processo de identificação quilombola se constitui 
passa pelo contexto de tensões sociais reedificadas desde os tempos da escravização negra, implicando o sentido de propriedade vinculado ao de senhor de gentes e terras em oposição ao de trabalhador livre e do uso comunal dos recursos do território.

A peculiaridade desta comunidade está vinculada territorialmente a um espaço que conjuga a maré, o rio, o mangue e o que restou da mata atlântica no local, a atividade da pesca, do catado, do extrativismo e das roças de subsistência. Os elos de solidariedade entre os seus membros têm vínculos com o território de memória geográfica e social, de memória de luta contra a escravidão e a opressão, marcada pelo trabalho nas fazendas e para fazendeiros que abandonaram suas terras por falência produtiva e que agora buscam retomar a posse formal pela dinâmica da valorização do mercado fundiário e também pela perda de poder político e de prestígio sobre a comunidade, principalmente caso ela se torne, de direito, titular da terra e produtora autônoma de seus destinos.

O reconhecimento público por parte do Estado sobre a ocupação secular destas terras pelos quilombolas, tanto como moradia quanto como lugar de passagem, lugar de extração de frutas, de fontes de água doce, de roças as meias, de lugares de pesca, de lugares de festa, de solidariedade, de religiosidade e de memória é fundamental, assim como é fundamental a titulação urgente do território para que se estabeleça o direito de fato daqueles que tradicionalmente vivem no local e o reconhecem como lugar de existência histórica e cultural, de subsistência econômica e de agência política da comunidade.

A noção de quilombo parece estar flutuando aí como forte significante de diferença entre os que são considerados e se consideram quilombolas e os que não o são; e ao mesmo tempo parece espelhar as continuidades entre o passado e o presente da opressão econômica e simbólica de proprietários contra os descendentes de africanos e da resistência contra ela. Neste caso, o processo de identificação coletiva traduz o fenômeno das contradições históricas nas relações de poder do presente que são oriundas dos tempos escravistas na região.

\section{Referências}

BARTH, F. (1998) Grupos Étnicos e suas Fronteiras. In: POUTIGNAT, P. e STREIFF-FENART, J. Teorias da Etnicidade. São Paulo, UNESP. 
BONFIM, W., MARCON, F. Relatório Antropológico do Território da Comunidade Quilombola Luziense. Aracaju: INCRA/FAPESE, 2009. (Relatório de pesquisa).

CATÁLAGO DOS INVENTÁRIOS JUDICIAIS DA COMARCA DE ESTÂNCIA: 1801-1805 / Coordenação Eugenia Andrade Vieira da Silva. Aracaju: TJ: Gráfica J. Andrade. 2004.

ENNES, M. \& MARCON, F. Das identidades aos processos identitários: repensando conexões entre cultura e poder. Sociologias (UFRGS. Impresso), v. 16, p. 274-305, 2014.

HALBWACHS, M. A Memória Coletiva. São Paulo: Ed. Centauro, 2004.

IBGE. Enciclopédia dos Municípios Brasileiros. Rio de Janeiro: IBGE, v. XIX, 1954, p. 406-408.

LEGISLAÇÂO SOBRE QUILOMBOS. In: Boletim Informativo do NUER. C. 2, n. 2. Florianópolis, NUER/UFSC, 2005. p. 151-201.

MOTT, L. Sergipe Del Rey: população, economia e sociedade. Governo de Sergipe, Secretaria de Estado da Educação e Cultura, Fundação Estadual de Cultura, 1986.

NUNES, M. T. Sergipe Colonial I. São Cristóvão: Editora da UFS; Rio de Janeiro: Tempo Brasileiro, 1989.

Sergipe Colonial II. Rio de Janeiro: Tempo Brasileiro, 1996.

NUNES, V. M. M. Poço de História. Memorial descritivo das ações do CENDOP em Poço Redondo. Canindé do São Francisco/SE: Programa Xingó/Área Temática Arqueologia e Patrimônio Histórico/CENDOP, 2001. Não Publicado.

WEBER, M. (2004). Relações Comunitárias étnicas. In: Economia e Sociedade. São Paulo, Imprensa Oficial.

Recebido em 25/05/2016

Aprovado em 30/06/2016 